\title{
Comparison of Surgical Tracheostomy and Percutaneous Dilatational Tracheostomy in Intensive Care Unit Patients
}

\author{
Hyun-Il Shin, Kyung-Il Jang, Kyung-Min Kim, and Inn-Chul Nam $\mathbb{D}$ \\ Department of Otolaryngology-Head and Neck Surgery, Incheon St. Mary's Hospital, The Catholic University of Korea \\ College of Medicine, Incheon, Korea
}

중환자실 환자에서 관혈적 기관 절개술과 경피적 확장 기관 절개술의 비교

신현일 · 장경일 · 김경민 · 남인철

가톨릭대학교 의과대학 인천성모병원 이비인후과학교실

Received November 28, 2018

Revised January 1,2019

Accepted January 30, 2019

Address for correspondence

Inn-Chul Nam, MD, PhD

Department of Otolaryngology-

Head and Neck Surgery,

Incheon St. Mary's Hospital,

The Catholic University of Korea

College of Medicine,

56 Dongsu-ro, Bupyeong-gu,

Incheon 21431, Korea

Tel $+82-32-280-5843$

Fax $+82-32-280-5157$

E-mail entnam@catholic.ac.kr
Background and Objectives Percutaneous dilatational tracheostomy (PDT) has become an increasingly popular method of establishing an airway for patients in need of chronic ventilator assistance. The aim of this study is to assess and compare two main strategies for doing tracheostomy: traditional open surgical tracheostomy (ST) and PDT.

Materials and Method We retrospectively reviewed medical records of 43 patients who underwent tracheostomy between the years 2016 and 2017. All patients were under intensive care unit (ICU) care and referred to the department of otolaryngology for tracheostomy. All tracheostomies were performed at the bedside using either percutaneous dilatational technique or open surgical technique by a single surgeon. In cases of PDT, either blind puncture technique without any guidance or laryngoscopy-guided puncture technique was used. Demographic and procedural variables and complications were compared between the two groups.

Results PDT was performed in 29 patients and ST in 14 patients. Of those who underwent PDT, 15 patients received the blind puncture technique and 14 patients laryngoscopy-guided puncture technique. The cricosternal distance was longer and the amount of blood loss and duration of the procedure was lesser in the PDT group. In the PDT group, there was no difference in blood loss nor in the duration of the procedure according to the puncture technique, whereas critical complications occurred more frequently when the blind technique was used. Subjective difficulty of the procedure is predictive of complications.

Conclusion The study show that PDT is a useful and safe procedure for ICU patients. Also, guidance on using the flexible laryngoscopy during PDT can prevent severe complications. Korean J Otorhinolaryngol-Head Neck Surg 2019;62(5):288-93

Key Words Complications · Intensive care unit · Tracheostomy.
서 론

경피적 확장 기관 절개술(percutaneous dilatational tracheostomy)은 1985년 Ciaglia 등'에 의해 처음 소개되었으며, 기

This is an Open Access article distributed under the terms of the Creative Commons Attribution Non-Commercial License (https://creativecommons.org/licenses/by-nc/4.0) which permits unrestricted non-commercial use, distribution, and reproduction in any medium, provided the original work is properly cited.
관을 직접 눈으로 확인하지 않고 기관 절개 튜브를 위치시킬 수 있는 술식으로, 시행 결정 후 침상 곁에서(bedside) 곧바 로 시행할 수 있어 환자를 이송하는데 따르는 위험을 줄일 수 있고, 수술장을 이용하지 않고 적은 인원으로 시행할 수 있어 경비가 절감되며, 시술 방법을 배우기 쉬운 장점이 있 다. ${ }^{23)}$ 이러한 장점으로 인해 그 시행 빈도가 점차 증가하고 있 으며, 실제로 본 술식이 소개된 이후 중환자에게 시행하는 기 
관 절개술의 빈도가 전체적으로 증가한 반면, 기존의 관혈적 기관 절개술의 시행 빈도는 가파르게 감소하여, 경피적 확장 기관 절개술이 기존의 관혈적 기관 절개술을 대체한다는 연 구 결과도 보고된 바 있다.)

실제로, 중환자실 환자는 전신상태가 좋지 않아 수술장으 로 옮겨 전신마취를 시행하기 어려운 경우가 많고, 다제내성 병원균에 감염되어 있는 경우가 많아 원내 감염 확산 방지를 위해 중환자실 내에서 기관 절개술을 시행해야 하는 경우가 많이 발생한다. 하지만 중환자실 내 침상 곁에서 관혈적 기관 절개술을 시행할 경우 적절한 무균상태의 유지나 충분한 수 술기구의 준비가 어려운 경우가 많으며, 술자의 불편한 자세, 부적절한 조명, 환자의 움직임, 소란스러운 주변 환경 등의 영 향으로 수술장에서의 시술보다 훨씬 어려운 점이 많다. 경피 적 확장 기관 절개술의 경우 기구가 키트(kit)의 형태로 사용하 기 편하게 구비되어 있으며, 조명이 필요없이 짧은 시간 안에 쉽게 시행할 수 있기 때문에 침상 곁에서 시행하기에 관혈적 기관 절개술에 비해 훨씬 편하다고 할 수 있다. 따라서 중환 자실 환자에게 기관 절개술을 시행할 때 경피적 확장 기관 절 개술이 전통적인 관혈적 기관 절개술에 비해 유용하다고 할 수 있다.

이러한 점에 입각하여 본 연구는, 기관 절개술이 필요한 중 환자실 환자에게 경피적 확장 기관 절개술을 적용한 경우 기 존의 관혈적 기관 절개술과 비교하여 그 유용성과 안전성을 확인하고 함을 목표로 하였다.

\section{대상 및 방법}

2016년 1월부터 2017년 12월까지 중환자실에서 기관 절개 술을 시행 받은 중환자실 환자들에 대한 후향적 의무기록 분 석을 시행하였다. 모든 환자는 중환자실 침상 곁에서 시술 받 았으며 관혈적 혹은 경피적 확장 기관 절개술을 시행 받았다. 모든 시술은 1 인의 이비인후과 전문의가 시행하였으며, 18 세 미만 환자, 기관 삽관 상태가 아닌 환자, 항응고 치료를 중단할 수 없는 환자는 제외하였다.

관혈적 기관 절개술은 수술장에서 시행하는 전통적인 기 관 절개술 방식으로 시행하였다. 경피적 확장 기관 절개술은 Ciaglia Blue Rhino Percutaneous Dilatational Tracheostomy $\mathrm{Kit}^{\circledR}($ Cook Critical Care, Bloomington, IN, USA)를 사용하여 시행하였다. 기구 세트내에 포함된 칼을 이용하여 약 $3 \mathrm{~mm}$ 길이의 피부 절개를 내고, $18 \mathrm{G}$ 바늘이 달린 주사기로 기관 천자를 가하고 이를 통해 기관 내로 유도 철심(guide wire)을 삽입 한 뒤, 확장기(gradual dilator)를 이용하여 기관 천자 창을 확장 한 후 유도 철심을 따라 관을 삽입하였다. 기
관 천자의 경우 경피적 확장 기관 절개술 시행 초기에는 아무 유도 없이 촉진을 통해 기관의 위치를 확인하고 천자한 후 주 사기를 역류시켜 공기가 흡입되는 것으로 기관 천자 여부를 확인하였다. 하지만 추후에는 기관 천자 전에 굴곡형 후두경 을 기관내 삽관 튜브(endotracheal intubation tube)로 삽입하 여 적절한 천자 위치를 기관 내에서 확인한 후 천자를 시행하 였다.

비교 인자로 환자의 나이, 성별, 해부학적 지표로서 윤상-흥 골 거리(cricosternal distance), 시술 시간, 출혈량, 시술자가 주 관적으로 판단한 시술 난이도(easy, medium, difficulty) 그리 고 합병증을 선택하여 관혈적 기관 절개술을 시행 받은 군과 경피적 확장 기관 절개술을 시행 받은 군 사이에 비교하였으 며, 경피적 확장 기관 절개술 군에서 기관 천자의 방법에 따 라 유도없이 천자한 군과 후두경 유도하 천자한 군으로 나누 어 비교하였다. 윤상-흥골 거리는 시술 시작 시에 시술 부위 를 노출하여 환자의 흥골절흔(sternal notch)부터 윤상연골 하연까지의 거리를 자를 이용하여 측정하였고, 시술 시간은 피부 절개부터 기관 절개관을 삽입 후 피부에 고정하기까지의 시간으로 계산하였다. 출혈량의 경우 시술 후 일정량의 생리식 염수를 석션 관과 통으로 통과시켜 전체 양을 측정한 후 투 입한 생리식염수 양을 제하여 측정하였으며, 두 시술 모두 출 혈량이 많지 않아 정확한 측정이 어려워 절대치를 측정하지 않고 0 10 mL, 10 20 mL의 범주로 나누어 측정하였다. 시 술 난이도는 술자가 시술 과정 중 어느 정도의 어려움을 느꼈 는가를 주관적으로 판단하여 결정하였으며, 예를 들어 해부 학적 구조물의 노출이 어렵거나, 기관 절개관의 삽입이 원활하 게 이루어지지 않았거나, 시술 중 출혈이 발생하여 지혈을 위 한 노력이 필요했던 경우 등은 난이도가 높은 경우로 판단하 였다.

통계적 검정으로 Chi-squared tests와 Fisher's exacts tests 를 이용하였으며, 통계적 유의성은 $p$-value $<0.05$ 로 설정하였 다. 본 연구는 본원 IRB의 승인을 받아 진행되었다(OC192E SI0024)

\section{결 과}

총 43명의 환자가 등록되었으며, 관혈적 기관 절개술은 14 명, 경피적 확장 기관 절개술은 29 명에서 시행되었다. 경피적 확장 기관 절개술을 받은 29 명의 환자 중 초기 15 명은 유도 없이 기관 천자를 시행하였고, 후기 14 명은 굴곡형 후두경 유 도 하에 기관 천자를 시행하였다. 평균 연령은 $60.9 \pm 8.0$ 세 (35 79세)였고, 남성 30명(69.8\%) 여성 13명(30.2\%)이었으며, 두 군 간에 나이, 성별의 차이는 없었다. 평균 기관 삽관 기간 
은 평균 12.7 일로 두 군 간의 차이는 없었으며, 시술 적응증으 로는 지속적인 기계환기, 지속적인 병상상태(bedridden state), 효과적인 호흡기 분비물 제거(pulmonary toilet), 근-신경계 결핍(neuromuscular deficit)의 순서를 보였으며 여러 적응 증이 혼재된 환자가 많았다. 삽관 기간 및 시술 적응증 역시 두 군 간에 유의한 차이는 없었다. 윤상-흥골 거리의 경우 경피적 확장 기관 절개술이 평균 $3.6 \mathrm{~cm}$ 로 관혈적 기관 절개 술의 $2.6 \mathrm{~cm}$ 에 비해 통계적으로 유의하게 길었다. 출혈량은 경피적 확장 기관 절개술의 경우가 관혈적 기관 절개술에 비 해 적은 경향을 보였으며, 시술 시간은 경피적 확장 기관 절 개술이 평균 8.0분으로 관혈적 기관 절개술의 21.6분에 비해 유의하게 짧았다. 술자가 판단한 시술의 난이도는 두 시술 방 법 간에 차이는 없었으며, 시술 후 합병증 발생빈도는 경피적 확장 기관 절개술을 시행 받은 환자에서 높은 경향 $(24.1 \%$ vs.
7.1\%)을 보였지만 통계적으로 유의하지는 않았다(Table 1). 경피적 확장 기관 절개술을 시행 받은 군에서 기관 천자 방 법에 따라 비교한 결과 출혈량, 시술 시간을 두 군 간에 차이 가 없었다. 시술 난이도와 부작용 발생 빈도의 경우 후두경 유도 하에 기관 천자를 시행한 경우 술자가 난이도를 쉽게 느끼고, 부작용 발생 빈도가 낮은 경향이 있었으나 통계적으 로 유의하지 않았다(Table 2). 하지만 합병증이 발생한 환자 를 분석하여 보면 유도 없이 기관 천자를 시행한 경우 중대한 합병증이 발생하는 경우가 많았다. 후두경 유도 하에 기관 천 자를 시행한 경우 시술 후 기관공 부위의 경미한 출혈 1 예만 발생한 반면, 유도 없이 기관 천자를 시행한 경우 경미한 피 하기종이 발생한 1 예를 제외하면 4 명의 환자에서 중대한 합 병증이 발생하였다. 2 명의 환자에서는 시술 과정 중 기도 확보 가 되지 않아 기관 삽관을 재시행 한 경우가 발생하였고, 1 명

Table 1. Comparison between ST and PDT

\begin{tabular}{|c|c|c|c|}
\hline Variables & PDT $(n=29)(\%)$ & ST $(n=14)(\%)$ & p-value \\
\hline Age & $60.3 \pm 7.9$ & $62.1 \pm 8.3$ & 0.89 \\
\hline $\operatorname{Sex}(M: F)$ & $23: 6$ & $7: 7$ & 0.07 \\
\hline Period of intubation & 12.8 & 12.3 & 0.62 \\
\hline \multicolumn{4}{|l|}{ Indication for tracheostomy } \\
\hline Prolonged ventilation & $20(69.0)$ & $11(78.6)$ & 0.91 \\
\hline Bedridden state & $21(72.4)$ & $8(57.1)$ & 0.63 \\
\hline Pulmonary toilet & $2(6.9)$ & $1(7.1)$ & 0.84 \\
\hline Neuromuscular deficit & $3(10.3)$ & $0(0)$ & 0.10 \\
\hline Cricosternal distance $(\mathrm{cm})$ & $3.6 \pm 0.81$ & $2.6 \pm 0.61$ & $0.02 *$ \\
\hline Estimated blood loss (mL) & & & $0.00^{*}$ \\
\hline $0-10$ & $25(89.3)$ & $9(64.3)$ & \\
\hline $10-20$ & $3(10.7)$ & $5(35.7)$ & \\
\hline Duration of procedure (min) & 8.0 & 21.6 & $0.04^{*}$ \\
\hline Ease of procedure & & & 0.82 \\
\hline Easy & $21(72.4)$ & $10(71.4)$ & \\
\hline Moderate & $6(20.7)$ & $2(14.3)$ & \\
\hline Difficult & $2(6.9)$ & $2(14.3)$ & \\
\hline Number of patients with complications & $7(24.1)$ & $1(7.1)$ & 0.24 \\
\hline
\end{tabular}

*p<0.05. PDT: percutaneous dilatational tracheostomy, ST: surgical tracheostomy

Table 2. Comparison between blind puncture and flexible laryngoscopy-guided puncture in the percutaneous dilatational tracheostomy group

\begin{tabular}{|c|c|c|c|}
\hline Variables & Blind $(n=15)(\%)$ & Laryngoscopy-guided $(n=14)(\%)$ & p-value \\
\hline Estimated blood loss (mL) & & & 0.87 \\
\hline $0-10$ & $12(86)$ & $13(93)$ & \\
\hline $10-20$ & $2(14)$ & $1(7)$ & \\
\hline Duration of procedure (min) & 8.5 & 7.9 & 0.53 \\
\hline Ease of procedure & & & 0.29 \\
\hline Easy & $8(53.3)$ & $13(92.9)$ & \\
\hline Moderate & $5(33.3)$ & $1(7.1)$ & \\
\hline Difficult & $2(13.3)$ & $0(0)$ & \\
\hline Number of patients with complications & $6(40)$ & $1(7.1)$ & 0.08 \\
\hline
\end{tabular}


Percutaneous Dilatational Tracheostomy in Intersive Care Unit Patients I Shin HI, et al.

Table 3. Analysis of association between parameters and complications

\begin{tabular}{lccc}
\hline \multicolumn{1}{c}{ Variables } & Without complication $(\mathrm{n}=35)(\%)$ & With complication $(\mathrm{n}=8)(\%)$ & $\mathrm{p}$-value \\
\hline PDT & $22(62.8)$ & $7(87.5)$ & 0.24 \\
Blind tracheal puncture in PDT & $9(60)$ & $6(40)$ & 0.08 \\
Male & $11(31.4)$ & $6(75)$ & 0.06 \\
Younger age & $18(51.4)$ & $2(25)$ & 0.18 \\
Less blood loss & $27(77.1)$ & $7(87.5)$ & 0.16 \\
Less time intubated & $14(40.0)$ & $5(62.5)$ & 0.24 \\
Less time for procedure & $17(48.6)$ & $4(50.0)$ & 0.94 \\
Cricosternal distance & $10(28.6)$ & $4(50.0)$ & 0.24 \\
Difficulty & & & $0.01^{*}$ \\
$\quad$ Easy & $28(80.0)$ & $3(37.5)$ & $2(25.0)$ \\
$\quad$ Medium & $6(2.9)$ & $6(75.0)$ & \\
Difficult & $1(2.9)$ & & \\
\hline
\end{tabular}

$* p<0.05$. PDT: percutaneous dilatational tracheostomy

의 환자에서는 기관 절개 튜브가 기관 내가 아닌 기관 주위 공 간으로 잘못 삽입되었으며, 1 명의 환자에서는 시술 후 광범위 한 피하기종과 함께 기흥, 기복증이 발생하였다.

합병증의 예측인자를 분석해 보면 시술방법 및 관혈적 기 관 절개술에서 기관 천자 방법은 합병증의 발생과 유의한 상 관관계를 보이지 않았다. 환자의 성별과 나이, 출혈량, 기관 삽 관 기간, 시술 시간, 해부학적 인자(윤상-흥골 거리) 등의 인 자 역시 합병증 발생과는 연관이 없었다. 시술의 난이도와 합 병증 발생률 간에는 유의한 상관관계가 있어, 술자가 시술이 어렵다고 느끼는 경우 합병증 발생률이 높아짐을 알 수 있다 (Table 3).

\section{고 찰}

경피적 확장 기관 절개술은 기존의 관혈적 기관 절개술에 비해 덜 침습적인 시술로 다양한 장점이 있어 기관 절개술이 필요한 중환자실 환자에게 시술 빈도가 점차 증가하고 있고 최근에는 중환자실이 아닌 일반 병실에서도 시행되고 있어 점차 그 적용범위를 확대해 가고 있다.,5) 관혈적 기관 절개술 과 경피적 확장 기관 절개술을 비교한 전향적 연구에 대한 메타분석 결과에 따르면, 경피적 확장 기관 절개술은 쉽게 시행할 수 있고, 출혈이 적으며, 시술 후 감염이 적은 장점이 있다.) 본 연구에서도 경피적 확장 기관 절개술이 관혈적 기 관 절개술에 비해 시술 과정에서의 출혈량이 유의하게 적었 으며, 시술 시간도 관혈적 기관 절개술의 21.6분에 비해 8.0 분으로 확연히 짧았다. 주관적이기는 하나 두 시술에 대한 술자의 시술 난이도 역시 두 군 간에 차이가 없어 기관 절개 술에 익숙한 술자인 경우 경피적 확장 기관 절개술도 어려움 없이 시행할 수 있음을 알 수 있다. 윤상-흥골 거리의 경우 경
피적 확장 기관 절개술이 유의하게 길었는데, 이는 해부학적 지표가 외부에서 잘 확인되고 목이 짧지 않은 환자에서 안전 한 시술이 가능한 경피적 확장 기관 절개술의 특징이 반영된 결과로 생각된다.

경피적 확장 기관 절개술은 이와 같은 장점이 있지만, 기관 을 직접 눈으로 확인하지 않고 천자를 하고, 기관전벽의 절 개나 절제 없이 확장을 통해 기관 절개창을 만드는 점으로 인해 기존의 관혈적 기관 절개술 과는 다른 양상의 합병증이 보고된다. ${ }^{8}$ 두 시술 간의 합병증을 비교한 메타분석에 따르 면, 전체적인 합병증의 빈도는 비슷하다. ${ }^{2.9)}$ 본 연구에서도 경 피적 확장 기관 절개술 군에서 약간 높은 경향을 보였으나, 통 계적으로 유의하지 않아 두 군 간의 합병증 발생빈도는 비슷 함을 알 수 있었다.

경피적 기관 절개술의 합병증은 일반적으로 초기와 후기 합 병증으로 나눌 수 있다.10) 초기 합병증에는 출혈, 감염, 기흥, 삽관 실패, 시술 중 튜브가 막히거나 예상치 못한 발관으로 인한 저산소증 등이 있고, 후기 합병증으로는 육아조직의 형 성으로 인한 기도 협착, 발관 실패, 발관 후 기도 폐색으로 인 한 호흡 장애, 기관 연화증, 기관 협착 및 기관 동맥루(tracheoinnominate artery fistula) 형성 등이 있다. ${ }^{11,12)}$ 대부분의 경 우 경미한 합병증으로 보고되며. 800 명의 중환자실 환자에 게 시행한 경피적 확장 기관 절개술을 분석한 연구에서 전체 합병증 발생률은 $4 \%$, 시술 중 발생한 합병증은 $2.1 \%$ 였으며, 한 명의 환자에서 기관 주위 공간으로의 잘못된 삽관이 발생 했음이 보고된 바 있다.13) 다른 연구에 따르면, 1985 2013까 지 발표된 자료를 토대로 경피적 확장 기관 절개술 합병증으로 인한 사망률이 $0.17 \%$ 이며, 사망 원인으로는 출혈(38\%), 기도 합병증(29.6\%), 기관천공(15.5\%), 기흥 $(5.6 \%)$ 등의 순서라고 보 고되었다. ${ }^{14)}$ 몇몇 연구자들에 의해 기관 주위 공간에 잘못 삽 
관 된 경우가 보고되었는데, 이는 경피적 확장 기관 절개술의 가장 큰 위험 요소 중의 하나이며, 그 빈도는 약 $1 \%$ 로 알려 져 있다. ${ }^{2,3}$ 이에 시술 중 기관지경이나 경부 초음파를 동시에 시행하여 유도바늘, 확장기, 기관 절개 튜브의 위치를 실시간 으로 관찰하면서 기관 손상이나 기관 주위 공간으로의 삽관 을 줄이는 방법도 소개되고 있으며, 기관 절개 튜브 삽입 후 기계 환기 전에 후두내시경을 통해 튜브가 적절한 위치에 삽 입 되었는지 확인함으로써 압력손상에 의한 피하기종, 기흥 등을 줄이는 방법도 발표된 바 있다. ${ }^{15,16)}$ 본 연구에서도 별도 의 유도없이 기관 천자를 시행하여 경피적 확장 기관 절개술 을 시행한 환자 1 명에서 기관 주위 공간으로 잘못 삽관되어 재시술한 경우가 있었다. 이후 굴곡형 후두경으로 기관 천자 위치를 확인하며 시행한 환자에서는 잘못 삽관된 경우가 발 생하지 않았다. 유도없이 기관 천자를 시행한 군과 후두경 유 도 하에 기관 천자를 시행한 군 간에 합병증 발생의 빈도는 차이가 없었지만, 중대한 합병증의 경우 유도 없이 천자를 시 행한 군에서 훨씬 많이 발생하여, 적절한 유도 과정을 통해 정확한 기관 천자 위치를 확인하고, 천자 과정을 실시간으로 확인하는 것이 안전하게 시술할 수 있는 방법임을 알 수 있다.

이 외에 경피적 확장 기관 절개술 시행 후 광범위한 피하기 종, 기흥, 기복증이 발생한 환자가 1 예 있었다. 경피적 확장 기 관 절개술 후 피하기종, 기흥 등이 발생할 수 있는 기전으로는 기관 벽의 손상에 의한 천공, 기관주위 공간으로의 삽관, 기 관 절개 튜브의 이탈 및 기계 환기와 관련된 압력손상 등을 들 수 있다. 500 명의 중환자실 환자에게 시행한 경피적 기관 절개술을 분석한 연구에서, 다양한 크기의 확장기로 여러 번 확장 시킨 그룹과 한 번 확장시킨 그룹 간에 각각 $6.5 \%, 9.2 \%$ 의 합병증이 발생함을 보고하였으며, 이는 단계적으로 여러 번 확장시켰을 경우 기관 벽에 가해지는 압력이 적고, 튜브가 들어갈 수 있는 충분한 공간이 확보되어 기관 주위로 잘못 삽 관되는 경우가 감소하고, 결과적으로 전체적인 합병증의 빈 도가 감소함에 기인한다고 하였다. ${ }^{17)}$ 본 연구 환자의 경우에 도 천자 후 기관전벽 확장 과정이 원활하지 않았으며, 이로 인해 튜브가 기관 내로 충분히 삽입되지 않은 상태에서 무리 하게 기계환기를 시행하여 광범위한 피하기종과 함께, 기흥 및 기복증까지 발생하였다. 경피적 확장 기관 절개술은 기관 전벽에 직접 절개를 가하거나 기관전벽 일부를 제거하는 관 혈적 기관 절개술과는 달리 확장기를 통해 기관 천자 부위를 넓히는 방법을 사용하므로 삽관 전에 충분한 기관공 확장이 중요하다고 하겠다.

합병증 발생에 대한 예측인자에 대한 분석 결과 시술자가 느끼는 시술 난이도와 합병증 발생 간에 유의한 상관관계가 있었다. 따라서 적절한 유도를 통한 기관 천자를 시행하고,
시술에 적절한 환자를 잘 선택하여 시행해야 합병증 발생을 예방할 수 있을 것으로 생각된다. 본 연구에서도 시행 초기 에는 후두경 유도없이 기관 천자를 시행한 경우 중대한 합병 증이 많이 발생하였다. 따라서 수술에 앞서 기관 주변의 해부 학적 지식을 충분히 숙지하고, 특히 경험이 부족한 초심자의 경우 후두경이나 기관지 내시경, 초음파 등을 이용하여 정확 한 천자 부위를 유도하여 시행하는 것이 중대한 합병증을 줄 이고 안전하게 시술할 수 있는 방법이라고 할 수 있겠다.

본 연구의 단점으로는 후향적 분석이라는 점과 분석에 이 용된 환자의 수가 적다는 점을 들 수 있다. 향후 더 많은 증례 분석 및 전향적인 연구를 통해 경피적 확장 기관 절개술의 유용성을 확인할 수 있을 것이며, 더 많은 환자에게 안전하 게 시행할 수 있을 것이다.

\section{Acknowledgments}

This work was supported by the National Research Foundation (NRF) of Korea grant funded by the Korea Government (MSIP) (2017R1C1B50576854).

\section{ORCID}

Inn-Chul Nam https://orcid.org/0000-0001-9246-1047

\section{REFERENCES}

1) Ciaglia P, Firsching R, Syniec C. Elective percutaneous dilatational tracheostomy. A new simple bedside procedure; preliminary report. Chest 1985;87(6):715-9.

2) Friedman Y, Fildes J, Mizock B, Samuel J, Patel S, Appavu S, et al. Comparison of percutaneous and surgical tracheostomies. Chest 1996;110(2):480-5.

3) Simpson TP, Day CJ, Jewkes CF, Manara AR. The impact of percutaneous tracheostomy on intensive care unit practice and training. Anaesthesia 1999;54(2):186-9.

4) Toursarkissian B, Zweng TN, Kearney PA, Pofahl WE, Johnson SB, Barker DE. Percutaneous dilational tracheostomy: Report of 141 cases. Ann Thorac Surg 1994;57(4):862-7.

5) Cohen O, Shnipper R, Yosef L, Stavi D, Shapira-Galitz Y, Hain M, et al. Bedside percutaneous dilatational tracheostomy in patients outside the ICU: A single-center experience. J Crit Care 2018;47: $127-32$.

6) Şahiner İT, Şahiner Y. Bedside percutaneous dilatational tracheostomy by Griggs technique: A single-center experience. Med Sci Monit 2017;23:4684-8.

7) Freeman BD, Isabella K, Lin N, Buchman TG. A meta-analysis of prospective trials comparing percutaneous and surgical tracheostomy in critically ill patients. Chest 2000;118(5):1412-8.

8) Delaney A, Bagshaw SM, Nalos M. Percutaneous dilatational tracheostomy versus surgical tracheostomy in critically ill patients: A systematic review and meta-analysis. Crit Care 2006;10(2):R55.

9) McCormick B, Manara AR. Mortality from percutaneous dilatational tracheostomy. A report of three cases. Anaesthesia 2005;60(5):490-5.

10) Grant CA, Dempsey G, Harrison J, Jones T. Tracheo-innominate artery fistula after percutaneous tracheostomy: Three case reports and a clinical review. Br J Anaesth 2006;96(1):127-31.

11) Ciaglia P, Graniero KD. Percutaneous dilatational tracheostomy. Results and long-term follow-up. Chest 1992;101(2):464-7.

12) Das P, Zhu H, Shah RK, Roberson DW, Berry J, Skinner ML. 
Tracheotomy-related catastrophic events: Results of a national survey. Laryngoscope 2012;122(1):30-7.

13) Díaz-Regañón G, Miñambres E, Ruiz A, González-Herrera S, HolandaPeña M, López-Espadas F. Safety and complications of percutaneous tracheostomy in a cohort of 800 mixed ICU patients. Anaesthesia 2008;63(11):1198-203.

14) Simon M, Metschke M, Braune SA, Püschel K, Kluge S. Death after percutaneous dilatational tracheostomy: A systematic review and analysis of risk factors. Crit Care 2013;17(5):R258.

15) Giri PC, Bellinghausen Stewart A, Dinh VA, Chrissian AA, Nguyen
HB. Developing a percutaneous dilatational tracheostomy service by medical intensivists: Experience at one academic institution. $\mathrm{J}$ Crit Care 2015;30(2):321-6.

16) Susarla SM, Peacock ZS, Alam HB. Percutaneous dilatational tracheostomy: Review of technique and evidence for its use. J Oral Maxillofac Surg 2012;70(1):74-82.

17) Kost KM. Endoscopic percutaneous dilatational tracheotomy: A prospective evaluation of 500 consecutive cases. Laryngoscope 2005;115(10 Pt 2):1-30. 